\title{
Survival is higher after repeat lung metastasectomy than after a first metastasectomy: Too good to be true?
}

\author{
Tom Treasure, MD, MS, FRCS, FRCP, ${ }^{\mathrm{a}}$ Tommaso Mineo, MD, ${ }^{\mathrm{b}}$ Vincenzo Ambrogi, MD, ${ }^{\mathrm{b}}$ and \\ Francesca Fiorentino, $\mathrm{PhD}^{\mathrm{c}}$
}

The authors of the International Registry of Lung Metastases reported that survival was higher for a second compared with a first metastasectomy operation after 5 and 10 years ( $44 \%$ vs $39 \%$ and $29 \%$ vs $25 \%$, respectively). ${ }^{1}$ Pastorino and colleagues ${ }^{1}$ wrote "The long-term outcome of patients who were treated by a second metastasectomy was remarkably good." The word "remarkably" provides the clue. The finding seemed to be too good to be true.

Similar observations have been made repeatedly for sarcoma, which is the most established clinical indication for lung metastasectomy. In a systematic review of 14 followup studies composed of 1357 patients, 579 received a repeat metastasectomy ( $43 \%$; range, $21 \%-79 \%){ }^{2}$ The observation that repeat metastasectomy was followed by higher survival has been made repeatedly.

- "Prognostic factors for increased survival included 3 or greater redo pulmonary operations..."

- "...patients with complete resection for recurrent pulmonary metastasis show a significantly better prognosis after repeat pulmonary metastasectomy."

- “...repeat metastasectomy for recurrent pulmonary metastasis also provided a favorable overall survival $(P=.041) . " 5$

- "Repeated and aggressive pulmonary resections for leiomyosarcoma metastases extend survival." 6

The practice of repeated metastasectomy has become part of the mantra of "treating cancer as a chronic illness.",

"...patients persistently free of the primary osteosarcoma who developed recurrent resectable metastatic disease of the lung should be considered for reoperation a second, third, or fourth time." 8

For colorectal cancer, there is a similar acceptance of repeated lung metastasectomy that increased from a rate of $15 \%$ to more than $20 \%$ from the 1960 s to 2000 s in an

\footnotetext{
From the Clinical Operational Research Unit, Department of Mathematics, ${ }^{\text {a }}$ University College London, London, United Kingdom; Thoracic Surgery, ${ }^{\mathrm{b}}$ Policlinic Tor Vergata University, Rome, Italy; and Francesca Fiorentino Cardiothoracic Surgery, ${ }^{\mathrm{c}}$ National Heart and Lung Institute Imperial College London, London, United Kingdom.

Received for publication Nov 25, 2014; revisions received Jan 17, 2015; accepted for publication Jan 29, 2015; available ahead of print March 20, 2015.

Address for reprints: Tom Treasure, MD, MS, FRCS, FRCP, University College London, Mathematics: Clinical Operational Research Unit, 4 Taviton Street, London WC1H 0BT, UK (E-mail: tom.treasure@gmail.com).

J Thorac Cardiovasc Surg 2015;149:1249-52

$0022-5223 / \$ 36.00$

Copyright (C) 2015 by The American Association for Thoracic Surgery

http://dx.doi.org/10.1016/j.jtcvs.2015.01.067
}

analysis of 51 studies including 3504 patients. ${ }^{9}$ Repeated metastasectomy was noted as practice in the review of lung metastasectomy in 1539 patients ${ }^{10}$ that formed part of the European Society of Thoracic Surgeons Lung Metastasectomy Project. ${ }^{11}$ It was also recorded in a later comprehensive analysis of colorectal cancer lung metastasectomy in 2925 patients. $^{12}$

In this statistical analysis, we take a closer look at how survival data are presented and suggest that a more skeptical view of this conclusion is warranted.

\section{GRAPHIC DISPLAYS OF SURVIVAL: WE SHOULD NOT ASSUME THAT THE LINES CAN BE COMPARED}

The Roman surgeons Tommaso Mineo and Vincenzo Ambrogi had for 25 years followed a policy of repeat metastasectomy. A Kaplan-Meier analysis undertaken for them showed that of patients who underwent multiple metastasectomy operations, $65 \%$ were alive at 5 years compared with $42 \%$ who underwent only 1 metastasectomy operation (Figure 1). In common with the authors of the landmark International Registry of Lung Metastases, they found this somewhat counterintuitive and invited the co-authors (Francesca Fiorentino and Tom Treasure) to review the analysis.

Figure 1 shows a familiar generic approach to displaying survival data that would be entirely appropriate if there were 2 treatment strategies randomly assigned. To permit comparison, a specified starting point is taken as time zero on the horizontal axis and the vertical axis shows the loss of patients due to death, accounting for censoring. The explicit purpose is to allow visual comparison. If the patients had been randomly assigned to either a policy of once only metastasectomy or a policy of repeated metastasectomy, then the inference might be drawn that a difference in survival was due to the different treatment plans. The method fails as a means of fair comparison if the patients themselves differ in ways that influence survival. Then the difference may be due to the patients' characteristics rather than the treatment they received. We will call the summary of these patient characteristics "survivability." Clinicians are aware of these patient characteristics, but they cannot all be retrieved from even a comprehensive research database and certainly not from a registry. ${ }^{13}$

\section{THE IMPORTANCE OF THE DENOMINATOR}

Estimates from various sources indicate that of all patients who are found to have metastases, less than 1 in 20 will 


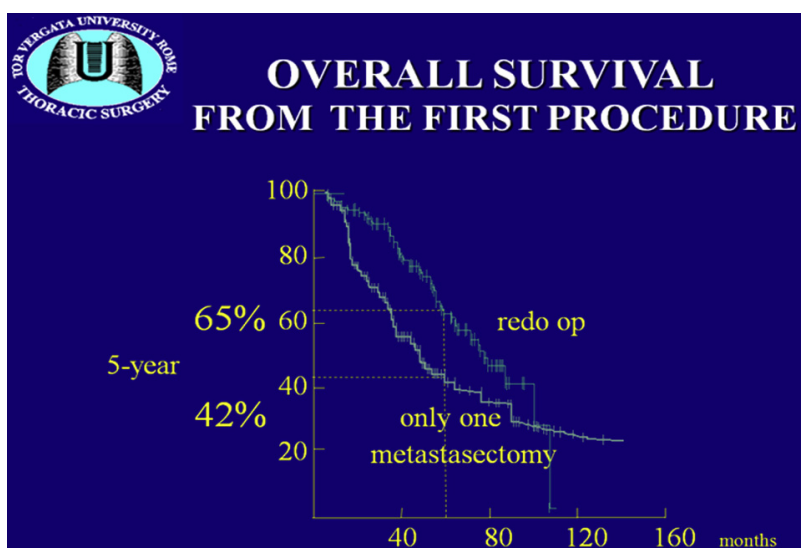

FIGURE 1. Kaplan-Meier analysis of 113 patients who underwent repeat metastasectomy operations alongside that for patients who underwent only 1 metastasectomy. Used with permission from Mineo TC, Ambrogi V, Tacconi F, Mineo D. Multi-reoperations for lung metastases. Future Oncol. 2015;11:37-41.

have a lung metastasectomy. ${ }^{14-18}$ With each successive metastasectomy, the degree of selection from the original denominator is greater; the apparent denominator diminishes as seen in the Roman surgeons' data (Table 1). We can deduce that approximately 1 in 100 of the original denominator received a second metastasectomy and 1 in 1000 received a fifth metastasectomy. These were not randomly selected from the original denominator; at the very least, they had to still be alive. Difference in survival cannot be ascribed to the number of metastasectomy operations they had undergone.

In a study of liver and lung metastasectomy from the Cleveland Clinic, denominators are provided. ${ }^{16}$ The upper line on the graph in Figure 2 relates to 25 patients who underwent both a liver and a lung metastasectomy. Seventeen patients who underwent a first liver metastasectomy had a subsequent lung metastasectomy, and 6 patients underwent a lung metastasectomy first. The lower line relates to 23 patients who had both liver and lung metastases but did not undergo any liver or lung metastasectomy. During the same time frame, 5787 patients had resections of primary colorectal carcinomas, 466 patients had resections of isolated colorectal hepatic metastases, and 72 patients had resections of isolated lung metastases. The selection of patients for metastasectomy was by individual clinical evaluation,

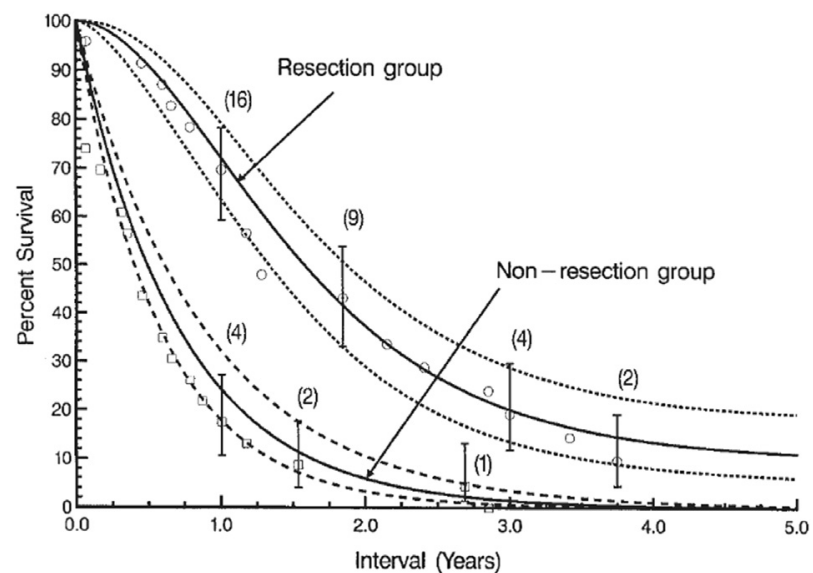

FIGURE 2. Survival after the last appearance or resection of metastases in the resection and nonresection groups. Each symbol represents a death, positioned according to Kaplan-Meier nonparametric estimates with vertical bars equivalent to 1 standard error. The solid lines are parametric survival estimates enclosed within confidence intervals (dashed lines) equivalent to 1 standard error. The numbers of patients living and being followed up are shown in parentheses.

and proceeding with the second metastasectomy operation was contingent on further individual clinical evaluation of the patient. The outcome was not reported on intention to treat but on completed treatment.

However sophisticated the analysis, it is impossible to know how much of the survival difference shown was due to inadvertent selection of patients inherently most likely to live longer (survivability) rather than an effect of sequential metastasectomy operations. Although the analysis is carefully justified in the text, it might be argued that it was misleading to put the lines next to each other in the depiction, implicitly inviting a comparison between 25 and 23 patients with lung and liver metastases who in the event (but not by intention to treat) had both or neither resected.

\section{READING THE SHAPE OF THE CURVE}

If a picture is worth a thousand words, it is worth studying the survival graph to see what the picture tells us. We are familiar with cancer survival curves that generally follow the shape of the lower lines in Figures 1-3. The upper line in each has an early more horizontal component not seen in natural cancer survival graphs. Lung metastases are

TABLE 1. Intraoperative intervals

\begin{tabular}{|c|c|c|c|c|c|c|c|}
\hline Metastasectomy operations & Patients & Interval before & Median months & Minimum & Maximum & $25 \%$ & $75 \%$ \\
\hline & & First & 14 & 0 & 70 & 5 & 24 \\
\hline$\geq 2$ & 113 & Second & 22 & 6 & 96 & 14 & 34 \\
\hline$\geq 3$ & 54 & Third & 23 & 10 & 64 & 17 & 39 \\
\hline$\geq 4$ & 31 & Fourth & 22 & 6 & 44 & 12 & 27 \\
\hline$\geq 5$ & 8 & Fifth & 13 & 4 & 96 & 11 & 13 \\
\hline 6 & 4 & Sixth & 8 & 7 & 70 & 7 & 9 \\
\hline
\end{tabular}

Unpublished data (T. Mineo, V. Ambrogi, June 2014). The available data can be obtained by request to the authors. 


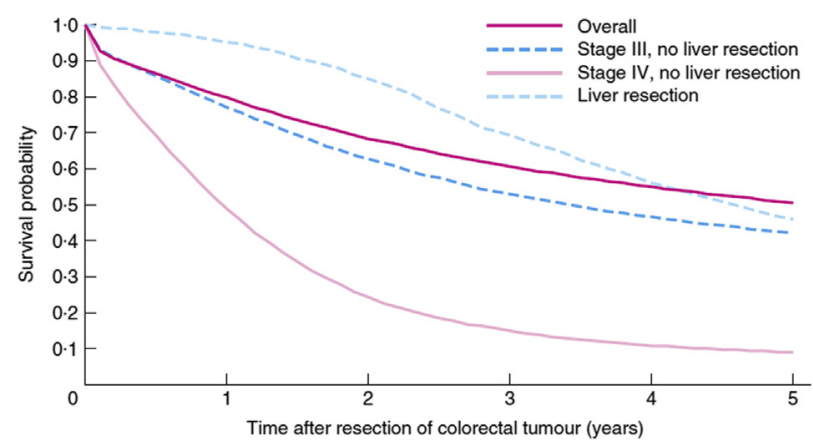

FIGURE 3. Kaplan-Meier survival curves for the overall study population, the patients with stage III or IV disease who did not undergo liver resection, and the patients who underwent liver resection.

rarely a cause of death, so it is unlikely that the early horizontal component (Figures 1 and 2) is due to survival benefit from lung metastasectomy. It is more likely to be due to conditional entry of patients judged clinically to be likely to survive for a reasonable time after operation. ${ }^{19}$

Figure 3 come from an analysis of 114,155 patients who underwent resection for a colorectal tumor, among whom 47,430 patients had liver metastases and $3116(6.6 \%)$ had them resected. We again see the horizontal component at the beginning of the survival curve of patients who had liver metastases resected. ${ }^{20}$ These plateau curves in Figures 1-3 are not natural cancer survival patterns but manifestations of immortal time bias. ${ }^{21-23}$

\section{RECOGNIZING THE EFFECT OF SELECTION}

No surgeon would disagree that it is important to be selective in offering patients lung metastasectomy. Less readily accepted is that survival attributed to metastasectomy may be due to the selection of patients who are inherently destined to survive longer. ${ }^{24,25}$ Selected patients have fewer metastases, longer intervals, and, in colorectal cancer, lower levels of carcinoembryonic antigen. ${ }^{26}$ These are not predictive of effectiveness of metastasectomy; they are prognostic factors for survival. ${ }^{27}$ Patients with slow progression and thus longer interval before the (re)appearance of metastases are more likely to have them surgically removed. ${ }^{28}$ The intraoperative intervals are in reality determined by conscious surgical decision rather than being governed by the behavior of the disease, as implied by the misnomer "disease-free interval" (Table 1).

\section{SURVIVABILITY AS A CONFOUNDING FACTOR FOR SURVIVAL}

The process of clinical assessment over time allows survivability to be identified in part, but not only because of slow progression of measureable lesions. This is deliberately or inadvertently included in the decision to offer metastasectomy. Selection on survivability is likely to be associated with subsequent survival. If there is a sequence of treatments, a patient must necessarily have survived the previous treatment and have been judged a likely future survivor to proceed to the next treatment. Clinical judgment of survivability is thus a confounding factor for the outcome of interest, which is survival.

\section{CONCLUSIONS}

Symptomatic or life-threatening metastases may be removed on clinical grounds. This is uncommon because lung metastases from carcinoma are rarely symptomatic and infrequently lethal. ${ }^{29}$

The lung is a relatively easy site to detect and monitor metastases. The white nodules show against the black radiolucent lung. Lung metastases can be resected with low risk and are a tempting target, and their removal may seem to be a rewarding exercise, but proof of a survival benefit is lacking. ${ }^{30-33}$

Oligometastasis is an increasingly exploited therapeutic opportunity, ${ }^{34}$ particularly for novel ablative techniques. Belief in benefit from ablation is an extrapolation from surgical resection, which is itself unproven. . $^{35,36}$

The inference that longer survival is due to the repeated operations cannot be reliably deduced from observational data. The impression of benefit may be because of the active selection of patients who have inherent survivability.

The observation of higher 5-year survival after a repeat metastasectomy than after a first metastasectomy has always been considered to be remarkable. ${ }^{1}$ The effect may not be due to the repeated surgery but to the effect of selection, amplified by its repetition.

When there are complex issues of case selection, and reselection, for successive treatments, random assignment to differing protocols and intention-to-treat analysis may be the only way to separate causation from association.

\section{Conflict of Interest Statement}

Authors have nothing to disclose with regard to commercial support.

\section{References}

1. Pastorino U, Buyse M, Friedel G, Ginsberg RJ, Girard P, Goldstraw P, et al. Long term results of lung metastasectomy: prognostic analyses based on 5206 cases. $J$ Thorac Cardiovasc Surg. 1997;113:37-49.

2. Treasure T, Fiorentino F, Scarci M, Moller H, Utley M. Pulmonary metastasectomy for sarcoma: a systematic review of reported outcomes in the context of Thames Cancer Registry data. BMJ Open. 2012;2:e001736.

3. Blackmon SH, Shah N, Roth JA, Correa AM, Vaporciyan AA, Rice DC, et al. Resection of pulmonary and extrapulmonary sarcomatous metastases is associated with long-term survival. Ann Thorac Surg. 2009;88:877-84.

4. Chen F, Miyahara R, Bando T, Okubo K, Watanabe K, Nakayama T, et al. Repeat resection of pulmonary metastasis is beneficial for patients with osteosarcoma of the extremities. Interact Cardiovasc Thorac Surg. 2009;9:649-53.

5. Chen F, Fujinaga T, Sato K, Sonobe M, Shoji T, Sakai H, et al. Significance of tumor recurrence before pulmonary metastasis in pulmonary metastasectomy for soft tissue sarcoma. Eur J Surg Oncol. 2009;35:660-5.

6. Burt BM, Ocejo S, Mery CM, Dasilva M, Bueno R, Sugarbaker DJ, et al. Repeated and aggressive pulmonary resections for leiomyosarcoma metastases extends survival. Ann Thorac Surg. 2011;92:1202-7. 
7. Treating cancer as a chronic illness. Available at: http://www.cancer.org/treatment/ survivorshipduringandaftertreatment/understandingrecurrence/whenyourcancer comesback/when-cancer-comes-back-treating-cancer-as-chronic-illness. Accessed March 3, 2015

8. Briccoli A, Rocca M, Salone M, Bacci G, Ferrari S, Balladelli A, et al. Resection of recurrent pulmonary metastases in patients with osteosarcoma. Cancer. 2005; 104:1721-5.

9. Fiorentino F, Hunt I, Teoh K, Treasure T, Utley M. Pulmonary metastasectomy in colorectal cancer: a systematic review and quantitative synthesis. J R Soc Med. 2010;103:60-6.

10. Pfannschmidt J, Hoffmann H, Dienemann H. Reported outcome factors for pulmonary resection in metastatic colorectal cancer. J Thorac Oncol. 2010;5(6 Suppl 2):S172-8.

11. Van Raemdonck D, Friedel G. The European Society of Thoracic Surgeons lung metastasectomy project. J Thorac Oncol. 2010;5(6 Suppl 2):S127-9.

12. Pfannschmidt J, Dienemann H. Surgical treatment of oligometastatic non-small cell lung cancer. Lung Cancer. 2010;69:251-8.

13. Williams WG. Uses and limitations of registry and academic databases. Semin Thorac Cardiovasc Surg Pediatr Card Surg Annu. 2010;13:66-70.

14. Wade TP, Virgo KS, Li MJ, Callander PW, Longo WE, Johnson FE. Outcomes after detection of metastatic carcinoma of the colon and rectum in a national hospital system. J Am Coll Surg. 1996;182:353-61.

15. Embun R, Fiorentino F, Treasure T, Rivas JJ, Molins L. Pulmonary metastasectomy in colorectal cancer: a prospective study of demography and clinical characteristics of 543 patients in the Spanish colorectal metastasectomy registry (GECMP-CCR), BMJ Open. 2013;3:e002787.

16. Robinson BJ, Rice TW, Strong SA, Rybicki LA, Blackstone EH. Is resection of pulmonary and hepatic metastases warranted in patients with colorectal cancer? $J$ Thorac Cardiovasc Surg. 1999;117:66-75.

17. Watanabe K, Saito N, Sugito M, Ito M, Kobayashi A, Nishizawa Y. Incidence and predictive factors for pulmonary metastases after curative resection of colon cancer. Ann Surg Oncol. 2013;20:1374-80.

18. Tampellini M, Ottone A, Bellini E, Alabiso I, Baratelli C, Bitossi R, et al. The role of lung metastasis resection in improving outcome of colorectal cancer patients: results from a large retrospective study. Oncologist. 2012;17:1430-8.

19. Glasziou P, Chalmers I, Rawlins M, McCulloch P. When are randomised trials unnecessary? Picking signal from noise. BMJ. 2007;334:349-51.

20. Morris EJ, Forman D, Thomas JD, Quirke P, Taylor EF, Fairley L, et al. Surgical management and outcomes of colorectal cancer liver metastases. Br J Surg. 2010; 97:1110-8.

21. Suissa S. Immortal time bias in observational studies of drug effects. Pharmacoepidemiol Drug Saf. 2007;16:241-9.
22. Suissa S. Immortal time bias in pharmaco-epidemiology. Am J Epidemiol. 2008; $167: 492-9$

23. Levesque LE, Hanley JA, Kezouh A, Suissa S. Problem of immortal time bias in cohort studies: example using statins for preventing progression of diabetes. BMJ. 2010;340:b5087.

24. Aberg T, Malmberg KA, Nilsson B, Nou E. The effect of metastasectomy: fact or fiction? Ann Thorac Surg. 1980;30:378-84.

25. Aberg T. Selection mechanisms as major determinants of survival after pulmonary metastasectomy. Ann Thorac Surg. 1997;63:611-2.

26. Gonzalez M, Poncet A, Combescure C, Robert J, Ris HB, Gervaz P. Risk factors for survival after lung metastasectomy in colorectal cancer patients: a systematic review and meta-analysis. Ann Surg Oncol. 2013;20:572-9.

27. Simms L, Barraclough H, Govindan R. Biostatistics primer: what a clinician ought to know-prognostic and predictive factors. J Thorac Oncol. 2013;8:808-13.

28. Fiorentino F, Treasure T. Pulmonary metastasectomy for colorectal cancer: making the case for a randomized controlled trial in the zone of uncertainty. J Thorac Cardiovasc Surg. 2013;146:748-52.

29. Treasure T, Milosevic M, Fiorentino F, Pfannschmidt J. History and present status of pulmonary metastasectomy in colorectal cancer. World J Gastroenterol. 2014; 20:14517-26.

30. Treasure T, Utley M. Surgical removal of asymptomatic pulmonary metastases: time for better evidence. BMJ. 2013;346:21-3.

31. Treasure T, Monson K, Fiorentino F, Russell C. Operating to remove recurrent colorectal cancer: have we got it right? BMJ. 2014;348:g2085.

32. Godlee F. Colorectal cancer: a cautionary tale. BMJ. 2014;348:g3311.

33. Treasure T, Milosevic M, Fiorentino F, Macbeth F. Pulmonary metastasectomy: what is the practice and where is the evidence for effectiveness? Thorax. 2014;69:946-9.

34. Treasure T. Oligometastatic cancer: an entity, a useful concept, or a therapeutic opportunity? J R Soc Med. 2012;105:242-6.

35. Palma DA, Salama JK, Lo SS, Senan S, Treasure T, Govindan R, et al. The oligometastatic state-separating truth from wishful thinking. Nat Rev Clin Oncol. 2014;11:549-57.

36. Ruers T, Punt C, van CF, Pierie JP, Borel-Rinkes I, Ledermann JA, et al. Radiofrequency ablation combined with systemic treatment versus systemic treatment alone in patients with non-resectable colorectal liver metastases: a randomized EORTC Intergroup phase II study (EORTC 40004). Ann Oncol. 2012;23: 2619-26.

Key Words: colorectal cancer, metastasectomy, surgical selection, confounding 